\title{
Differences in Synaptic Dysfunction Between rTg4510 and APP/PS1 Mouse Models of Alzheimer's Disease
}

\author{
Simon Gelman*, Jonathan Palma, Geoffrey Tombaugh and Afshin Ghavami \\ Psychogenics, Inc., Montvale, NJ and Tarrytown, NY, USA
}

Accepted 31 August 2017

\begin{abstract}
Genetically modified mice have provided insights into the progression and pathology of Alzheimer's disease (AD). Here, we have examined two mouse models of AD: the rTg4510 mouse, which overexpresses mutant human Tau gene, and the APP/PS1 mouse, which overexpresses mutant human genes for amyloid precursor protein and presenilin 1. Both models exhibit deficits in hippocampal function, but comparative analyses of these deficits are sparse. We used extracellular field potential recordings in hippocampal slices to study basal synaptic transmission (BST), paired-pulse facilitation (PPF), and long-term potentiation (LTP) at the Schaffer collateral-CA1 pyramidal cell synapses in both models. We found that 6-7, but not 2-3-month-old rTg4510 mice exhibited reduced pre-synaptic activation (fiber volley (FV) amplitude, $\sim 50 \%$ ) and field excitatory post-synaptic potential (fEPSP) slope $(\sim 40 \%)$ compared to wild-type controls. In contrast to previous reports, BST, when controlled for FV amplitude, was not altered in rTg4510. APP/PS1 mice (2-3 mo and 8-10 mo) had unchanged FV amplitude compared to wild-type controls, while fEPSP slope was reduced by $\sim 34 \%$ in older mice, indicating a deficit in BST. PPF was unchanged in 8-10-month-old APP/PS1 mice, but was reduced in 6-7-month-old rTg4510 mice. LTP was reduced only in older rTg4510 and APP/PS1 mice. Our data suggest that BST deficits appear earlier in APP/PS1 than in rTg4510, which exhibited no BST deficits at the ages tested. However, FV and synaptic plasticity deficits developed earlier in $\mathrm{rTg} 4510$. These findings highlight fundamental differences in the progression of synaptic pathology in two genetically distinct models of AD.
\end{abstract}

Keywords: Amyloidosis, electrophysiology, synaptic dysfunction, tauopathy

\section{INTRODUCTION}

Alzheimer's disease (AD) is a neurodegenerative disease, resulting in a severe and progressive memory impairment, deterioration of cognitive abilities, changes in behavior, and loss of language and, in late stages, a production of motor deficits similar to parkinsonism [1, 2]. Pathologically, AD is characterized by formation and accumulation of extracellular amyloid plaques and intracellular neurofibrillary tangles (NFTs) in cortical and sub-cortical brain regions $[3,4]$. Investigations of familial forms of AD led to

\footnotetext{
${ }^{*}$ Correspondence to: Simon Gelman, Psychogenics, Inc., 100 Philips Parkway, Montvale, NJ 07645, USA. Tel.: +1 201746 8776; E-mail: simon.gelman@psychogenics.com.
}

discoveries of genetic mutations in amyloid precursor protein gene (APP) on chromosome 21 [5-10], presenilin-1 (PSEN1) on chromosome 14 [11, 12], and presenilin-2 (PSEN2) on chromosome 1 [13, 14], which cause autosomal dominant forms of AD. Additionally, genetic studies of patients with an autosomal dominant frontotemporal dementia and parkinsonism (FTDP-17) identified several mutations of tau gene on chromosome $17[15,16]$. Tau gene encodes a microtubule-associated protein tau (MAPT). NFTs detected in $\mathrm{AD}$ and other tauopathies are aggregates of filamentous hyperphosphorylated tau [17-20]. Subsequently, several transgenic mouse models have been developed that overexpress human ADassociated mutations. These models partially recapitulate $\mathrm{AD}$ pathology and its progression and are useful 
tools in both studies of genotype-to-phenotype relationships and the development of therapeutic agents.

One extensively utilized model is a double transgenic mouse $\left(\mathrm{APP}_{\mathrm{swe}} / \mathrm{PS} 1_{\mathrm{M} 146 \mathrm{~L}}\right)$, which overexpresses mutated human amyloid precursor protein and presenilin-1, resulting in accelerated $\mathrm{A} \beta$ deposition [21-23]. A newer model of tauopathy is the $\operatorname{rgg}(\operatorname{tauP} 301 \mathrm{~L}) 4510$ mouse, which overexpresses mutated human tau protein $[24,25]$. Generally, these and related lines of mice exhibit an age-dependent and region-specific progression of neuropathology [26-28]. In the $\mathrm{APP}_{\text {swe }} / \mathrm{PS}_{\mathrm{M} 146 \mathrm{~L}}$ mouse, amyloid- $\beta$ $(A \beta)$ deposition begins at 3-4 months of age in frontal cortex and hippocampus and progressively increases with age $[22,29]$. This mouse also exhibits abnormal tau phosphorylation, but lacks NFTs [30]. Neuronal loss, however, was detected only in aged mice at about 22-24 months [31-33]. rTg(tauP301L) 4510 mice develop phosphorylated tau pretangles by 2-3 months of age, with NFTs appearing in the cortex by 4 months and in the hippocampus by 5.5 months. Additionally, significant hippocampal neuronal degeneration is already present at about 5 months of age and continues to progress rapidly. Ten-month-old mice exhibit gross brain atrophy $[24,25]$.

There are relatively few studies that systematically examine electrophysiological deficits in these mice [30]. Moreover, to our knowledge, there are no studies that make side-by-side comparisons of the same electrophysiological parameters in different models. Additionally, the differences in the extent and time course of changes in basal synaptic transmission (BST) and synaptic plasticity in these and other AD models [26-28, 30, 34, 35] may be due to differences in the nature of mutations, mouse strains, or experimental conditions. Therefore, it is important to examine progression of functional deficits utilizing a standardized approach, as we did in this work.

In this paper, we compared electrophysiological phenotypes and their progression between $\mathrm{APP}_{\text {swe }}$ / PS1 $1_{\mathrm{M} 146 \mathrm{~L}}$ and $\mathrm{rTg}(\mathrm{tauP301L}) 4510$ mice. We focused on basal synaptic transmission, and short- and longterm plasticity in CA1 area of the hippocampus.

\section{MATERIALS AND METHODS}

\section{Animals}

We utilized rTg(tauP301L)4510 mice (catalog \# 024854 - $\operatorname{Tg}$ (Camk2a-tTA)1Mmay Tg(tetO-MAPT* $\mathrm{P} 301 \mathrm{~L}) \# \mathrm{Kha} / \mathrm{J})$ that were purchased from the Jack- son Laboratory (Bar Harbor, ME, USA) and $\mathrm{APP}_{\text {swe }}$ /

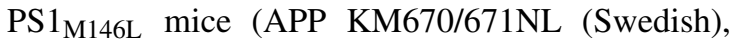
PSEN1 M146L) [21, 36] bred at Psychogenics (Tarrytown, NY, USA). After receipt, mice were housed in cages in same-genotype groups of 5 animals each and maintained on a 12/12-h light/ dark cycle. The room temperature was maintained between $20^{\circ} \mathrm{C}$ and $23^{\circ} \mathrm{C}$ with a relative humidity maintained between $30 \%$ and $70 \%$. Chow and water were provided ad libitum.

\section{Electrophysiology}

All procedures were performed in accordance with institutional IACUC guidelines. Mice were sacrificed by decapitation under isoflurane anesthesia. Procedures for slice preparation and electrophysiological recordings using interface slice chambers followed a well-established practice in the field [37-43]. The brains were dissected and immediately cooled in ice cold oxygenated $\left(95 \% \mathrm{O}_{2} / 5 \% \mathrm{CO}_{2}\right)$ ACSF with the following composition (in $\mathrm{mM}$ ): $\mathrm{NaCl} 124, \mathrm{KCl} 3.5$, $\mathrm{NaH}_{2} \mathrm{PO}_{4}$ 1.2, $\mathrm{NaHCO}_{3} 26, \mathrm{CaCl}_{2}$ 2.5, $\mathrm{MgSO}_{4}$ 1.2, glucose 11, pH 7.4. Hippocampi were dissected from the forebrain; transverse hippocampal slices $(400$ micron) were prepared with a tissue chopper (Stoelting tissue slicer, Stoelting Co., IL, USA) [41-45] and maintained at $32^{\circ} \mathrm{C}$ in a dual interface chamber (Scientific Systems Design, Mississauga, Ontario, Canada) continually oxygenated $\left(95 \% \mathrm{O}_{2} / 5 \% \mathrm{CO}_{2}\right)$ and perfused at $1-2 \mathrm{ml} / \mathrm{min}$ with ACSF and allowed to recover for $90 \mathrm{~min}$ prior to any recordings. A platinum/iridium recording electrode and a concentric bipolar stimulating electrode (FHC, Bowdoinham, ME, USA) were positioned on the surface of the slice in the stratum radiatum region of CA1 (interelectrode distance: $300-500 \mu \mathrm{m})$. Field excitatory post-synaptic potentials (fEPSPs) were evoked by biphasic square wave stimuli with increasing amplitudes $(0-400 \mu \mathrm{A} ; \Delta=20 \mu \mathrm{A}$; duration: $120 \mu \mathrm{s})$ at a frequency of $0.066 \mathrm{~Hz}$ with an STG 4004 stimulator (Multichannel Systems, Reutlingen, Germany). fEPSP signals between $0.1 \mathrm{~Hz}$ and $1 \mathrm{kHz}$ (filtered using high-pass and low-pass Bessel filters of the amplifier) were amplified using a DP-311 differential amplifier (Warner Instruments, Hamden, Connecticut, USA) and acquired at $20 \mathrm{kHz}$ sampling rate with Axon Digidata 1550A (Molecular Devices, Sunnyvale, California, USA). Waveforms were averaged $(n=3)$ per stimulus level. The initial linear slope of fEPSPs was used as a measure of the postsynaptic response and fiber volley (FV) amplitude 
A

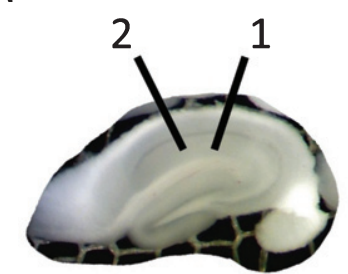

D

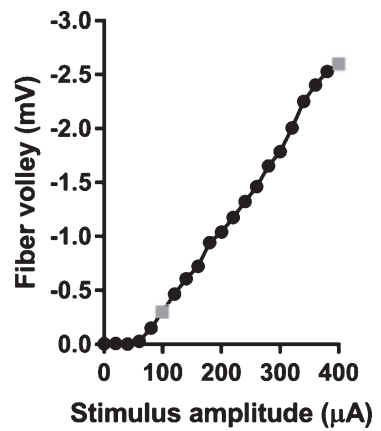

B

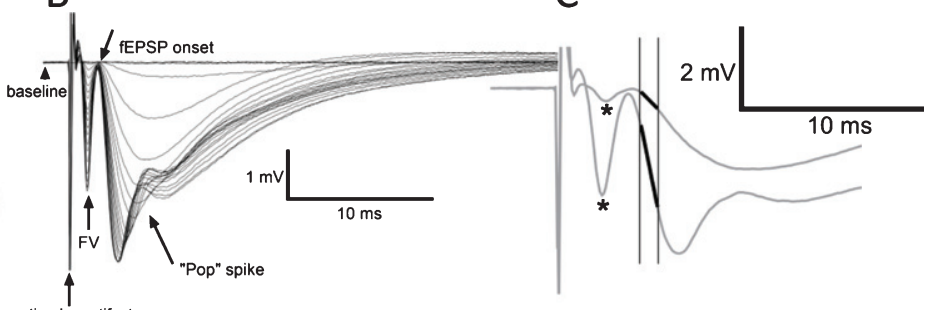

E

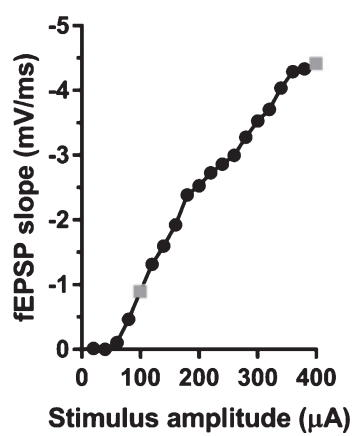

C

F

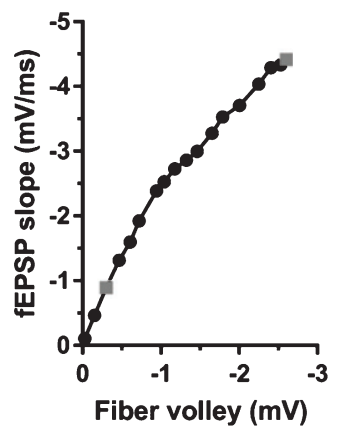

Fig. 1. Measurement of several parameters of response in CA1 area elicited by stimulation of Schaffer collaterals. A) A photograph of an interface slice preparation, depicting placement of stimulating (1) and recording electrode (2). B) Example of typical responses evoked in CA1 area to a series of stimuli with increasing stimulus intensities. Note a clearly distinguishable fiber volley, fEPSP onset, and a "pop" spike that appears at larger stimulus intensities. C) Two enlarged traces from (B) showing responses to stimuli of 100 and $400 \mu \mathrm{A}$. Asterisks depict peaks of fiber volleys (FV). FV amplitude was defined as a difference between the peaks and baseline for each trace. fEPSP slope was measured as a slope of the initial linear portion of the fEPSP (depicted as bold lines). D) Graph depicting measurements of FV amplitude versus stimulus amplitude from the data traces shown in (B). E) Graph depicting measurements of fEPSP slope versus stimulus amplitude from the data shown in (B). F) Graph depicting measurements of fEPSP slope versus FV amplitude from the data shown in (B). Points rendered as gray symbols in (D), (E), and (F) represent measurements of the enlarged traces in (C).

as a measure of the strength of the pre-synaptic activation (i.e., axonal depolarization). Figure 1 depicts a typical example of the recorded waveform and measurements obtained from such waveforms for each slice. Synaptic function was evaluated by constructing input-output relationships in which the fEPSP slope measures were plotted against either stimulus intensity or fiber volley amplitude. BST, as defined in this study, refers to measures of post-synaptic output (fEPSP) as a function of a given input (FV). Paired pulse facilitation (PPF) was tested using $50 \mathrm{~ms}$ inter-pulse interval, which is a commonly used interval. Long-term potentiation (LTP) experiments were performed at a stimulus intensity that elicited approximately $40 \%$ of the maximal response (fEPSP slope), and a 20-min stable baseline was recorded prior to inducing LTP. LTP was induced with three 1-s duration $100 \mathrm{~Hz}$ tetanus trains (high frequency stimulation, HFS), with 5-min inter-train intervals [45]. Responses were followed for an hour following the last tetanus.

\section{Statistical analysis}

Raw data were analyzed with pClamp10 (Molecular Devices, Sunnyvale, California, USA). Statistical analysis included two-way ANOVA followed by a multiple comparison tests, unpaired $t$-test, or Kolmogorov-Smirnov (K-S) test, where appropriate. LTP time-course data (fEPSP slope) were expressed as a percent of baseline for each slice. Data are presented as the mean and standard error of the mean (s.e.m.).

\section{RESULTS}

\section{Basal synaptic transmission in young and old APP/PS1 and rTg4510 mice}

We examined basal synaptic transmission and the strength of pre-synaptic Schaffer collaterals activation at different ages in rTg4510 and APP/PS1 mice 
A

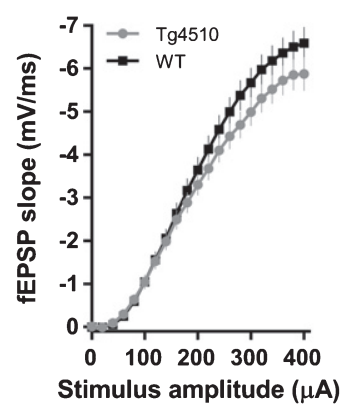

D

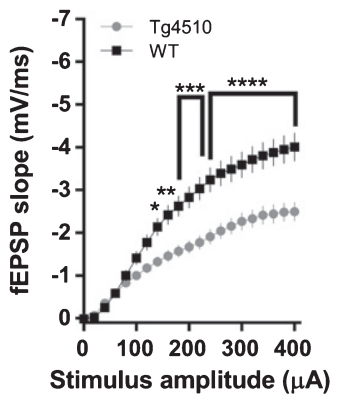

B

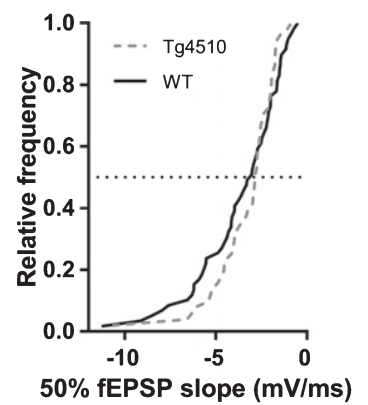

E

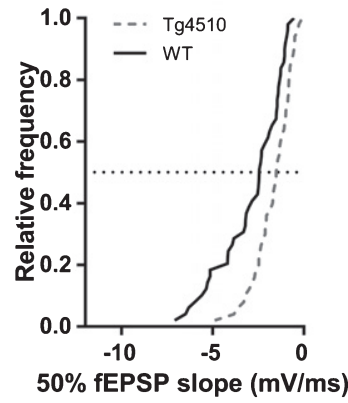

C

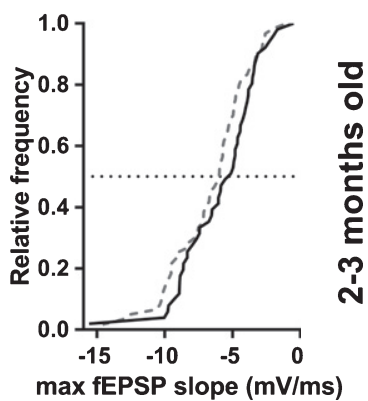

F

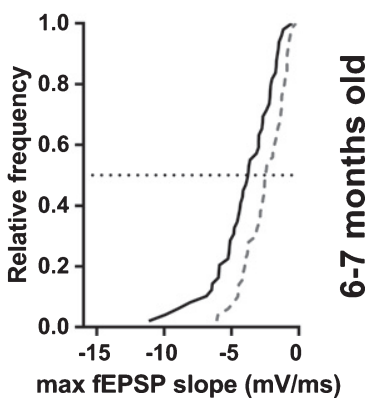

Fig. 2. Post-synaptic responses in CA1 pyramidal cells of hippocampus elicited with Schaffer collaterals stimulation in rTg4510 mice. A) fEPSP slopes plotted against stimulus amplitude from 2-3-month-old mice (WT $n=60$ slices from 9 animals; $\mathrm{rTg} 4510 n=51$ slices from 8 animals; 2-way ANOVA; genotype: $\mathrm{F}(1,2289)=16.5, p<0.0001$; stimulus amplitude: $\mathrm{F}(20,2289)=152.7, p<0.0001$; interaction: $\mathrm{F}(20$, $2289)=0.67, p=0.8590 ;$ ). B) Cumulative distribution histogram of responses (fEPSP slopes) elicited with a $50 \%$ stimulus amplitude (200 $\mu \mathrm{A})$ in 2-3-month-old animals (K-S test, $D=0.1785, p=0.3483$ ). C) Cumulative distribution histogram of responses (fEPSP slopes) elicited with a $100 \%$ stimulus amplitude $(400 \mu \mathrm{A})$ in 2-3-month-old animals (K-S test, $\mathrm{D}=0.2039, p=0.2018)$. D) fEPSP slopes plotted against stimulus amplitude from 6-7-month-old mice (WT $n=49$ slices from 9 animals; $\operatorname{rTg} 4510 n=50$ slices from 8 animals; (2-way ANOVA; genotype: $\mathrm{F}(1,2037)=209.2, p<0.0001$; stimulus amplitude: $\mathrm{F}(20,2037)=60.1, p<0.0001$; interaction: $\mathrm{F}(20,2037)=4.251, p<0.0001$; asterisks indicate result of Bonferroni's multiple comparisons test). E) Cumulative distribution histogram of responses (fEPSP slopes) elicited with a $50 \%$ stimulus amplitude $(200 \mu \mathrm{A})$ in 6-7-month-old animals (K-S test, $\mathrm{D}=0.3118, p=0.0162)$. F) Cumulative distribution histogram of responses (fEPSP slopes) elicited with a $100 \%$ stimulus amplitude $(400 \mu \mathrm{A})$ in 6-7-month-old animals (K-S test, $\mathrm{D}=0.309, p=0.0177)$.

(rTg4510:2-3 mo and 6-7 mo; APP/PS1 : 2-3 mo, $8-10 \mathrm{mo}$, and $24 \mathrm{mo}$ ). fEPSP slope was not altered in 2-3-month-old rTg4510 mice compared to wild-type (WT) controls, as can be seen from the input-output curves depicted in Fig. 2A. Further analysis of cumulative distributions of fEPSP slopes at $50 \%(200 \mu \mathrm{A})$ and $100 \%(400 \mu \mathrm{A})$ of stimulus amplitude revealed no difference between transgenic and WT animals (Fig. 2B, C). At 6-7 months of age, analysis of inputoutput relationship revealed a significant reduction of fEPSP slopes in rTg4510 mice compared to WT controls (Fig. 2D). Likewise, cumulative distributions of rTg4510 fEPSP slopes at $50 \%(200 \mu \mathrm{A})$ and $100 \%(400 \mu \mathrm{A})$ of stimulus amplitude were shifted to smaller values compared to WT controls (Fig. 2E, F). Activation of Schaffer collaterals spanning almost entire range of stimulus amplitudes in 2-3-month-old
rTg4510 mice was not different from WT controls, as can be seen from fiber volley input-output curves and cumulative distributions at $50 \%(200 \mu \mathrm{A})$ of stimulus amplitude (Fig. 3A, B). However, at the largest stimulus amplitude $(400 \mu \mathrm{A})$, we observed a $21 \%$ reduction in fiber volleys in $\mathrm{rTg} 4510$ mice $(-2.17 \mathrm{mV} \pm 0.23 \mathrm{SEM} ; n=51$ slices $)$ compared to WT controls $(-2.73 \mathrm{mV} \pm 0.19$ SEM; $n=61$ slices; Fig. 3A). Cumulative distribution at $100 \%(400 \mu \mathrm{A})$ of stimulus amplitude of $\mathrm{rTg} 4510$ fiber volleys was shifted to smaller values $(p=0.0260$, KolmogorovSmirnov test; Fig. 3C). At 6-7 months of age, analysis of input-output relations revealed a significant reduction of fiber volley amplitudes in $\mathrm{rTg} 4510$ mice compared to WT controls (Fig. 3D). Likewise, cumulative distributions of rTg4510 fiber volley amplitudes at $50 \%(200 \mu \mathrm{A})$ and $100 \%(400 \mu \mathrm{A})$ of 
A

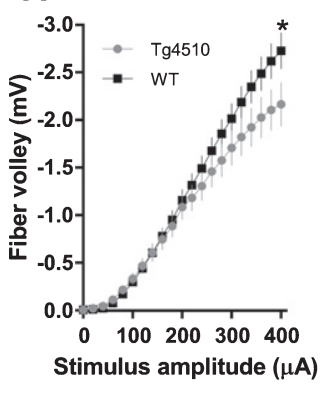

D

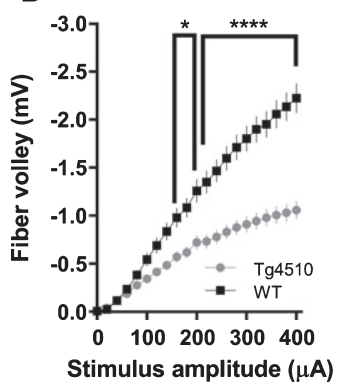

B

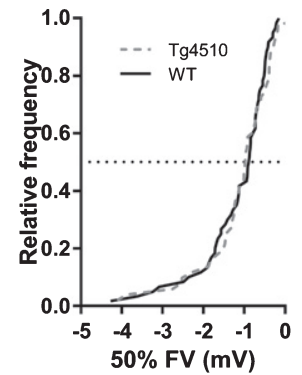

E

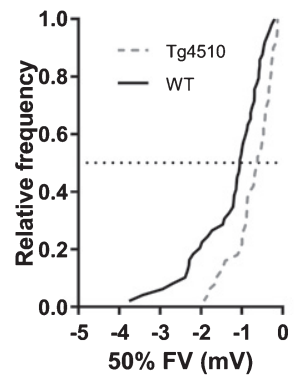

C

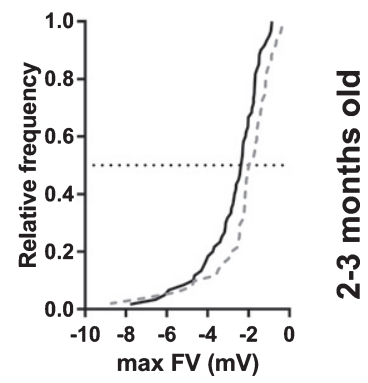

$F$

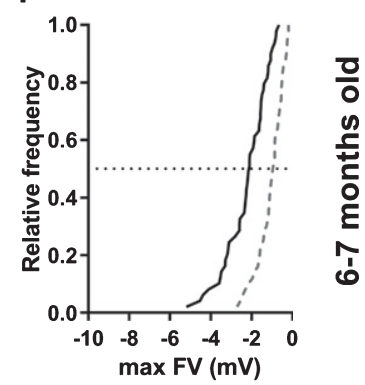

Fig. 3. Activation (fiber volley amplitudes) of Schaffer collaterals in CA1 area in rTg4510 mice. A) FV amplitudes plotted against stimulus amplitude from 2-3-month-old mice (WT $n=60$ slices from 9 animals; rTg4510 $n=51$ slices from 8 animals; (2-way ANOVA; genotype: $\mathrm{F}(1,2289)=17.06, p<0.0001$; stimulus amplitude: $\mathrm{F}(20,2289)=88.61, p<0.0001$; interaction: $\mathrm{F}(20,2289)=1.249, p=0.2037$; asterisk indicates result of Bonferroni's multiple comparisons test). B) Cumulative distribution histogram of FVs elicited with a $50 \%$ stimulus amplitude $(200 \mu \mathrm{A})$ in 2-3-month-old animals (K-S test, $\mathrm{D}=0.1353, p=0.6939)$. C) Cumulative distribution histogram of FVs elicited with a $100 \%$ stimulus amplitude $(400 \mu \mathrm{A})$ in 2 -3-month-old animals (K-S test, $\mathrm{D}=0.2725, p=0.0333)$. D) FV amplitudes plotted against stimulus amplitude from 6-7-month-old mice (WT $n=49$ slices from 9 animals; rTg4510 $n=50$ slices from 8 animals; (2-way ANOVA; genotype: $\mathrm{F}(1,2037)=410.3, p<0.0001$; stimulus amplitude: $\mathrm{F}(20,2037)=78.24, p<0.0001$; interaction: $\mathrm{F}(20,2037)=10.55, p<0.0001$; asterisks indicate result of Bonferroni's multiple comparisons test). E) Cumulative distribution histogram of FVs elicited with a 50\% stimulus amplitude $(200 \mu \mathrm{A})$ in 6-7-month-old animals (K-S test, $\mathrm{D}=0.351, p=0.0045)$. F) Cumulative distribution histogram of FVs elicited with a $100 \%$ stimulus amplitude $(400 \mu \mathrm{A})$ in 6-7-month-old animals (K-S test, $\mathrm{D}=0.5371, p<0.0001)$.

stimulus amplitude were shifted to smaller values compared to WT controls (Fig. 3E, F).

Synaptic transmission in 2-3-month-old APP/PS1 mice was not different from WT controls, as can be seen from fEPSP slope input-output curves and cumulative distributions of responses elicited by stimulus amplitudes of $50 \%$ and $100 \%$ of maximum (Fig. 4A-C). Older mice (8-10 mo) showed $\sim 34 \%$ reduction in fEPSP slope at maximum stimulus amplitude (Fig. 4D, see figure legend for statistical details). Cumulative distributions of APP/PS1 fEPSP slopes at $50 \%(200 \mu \mathrm{A})$ and $100 \%(400 \mu \mathrm{A})$ of stimulus amplitude were shifted to smaller values compared to WT controls (Fig. 4E, F). In stark contrast to rTg4510 mice, APP/PS1 mice exhibited no change in fiber volley amplitude either at 2-3 months or 8-10 months of age (Fig. 5).

A clear difference of the effect of P301L (rTg4510) and APP/PS1 mutations on basal synaptic trans- mission emerged, when fEPSP slopes were plotted against fiber volley amplitudes. At 2-3 months of age, basal synaptic transmission was not effected in rTg4510 and APP/PS1 mice (Fig. 6A, C). However, 8-10-month-old APP/PS1 showed marked reduction of basal synaptic transmission, in contrast to unchanged BST in rTg4510 mice (Fig. 6B, D). In 6-7-month-old rTg4510 mice, observed reduction in fEPSP slope was correlated with the reduction of fiber volley amplitude (Figs. 2D and 3D). Controlling for this reduction by plotting fEPSP slope versus fiber volley amplitude eliminated an apparent deficit in BST (fEPSP slope versus fiber volley) (Fig. 6B). However, in 8-10-month-old APP/PS1 mice, reduction of fEPSP slope was not correlated with fiber volley amplitude, which was not changed, and therefore, when fEPSP slope was plotted against fiber volley amplitude, a genuine deficit in BST was observed (Fig. 6D). This deficit was increased in 24- 
A

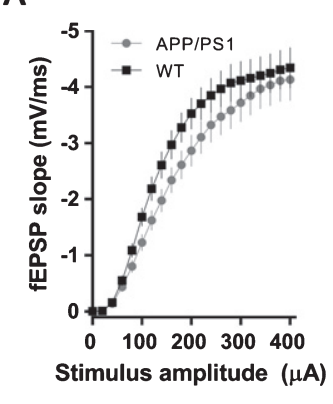

D

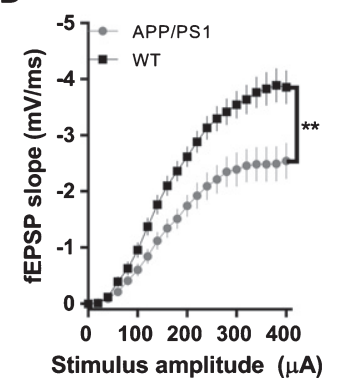

B

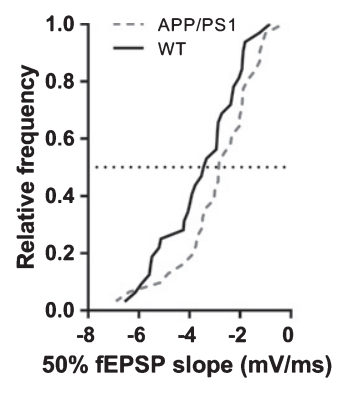

E

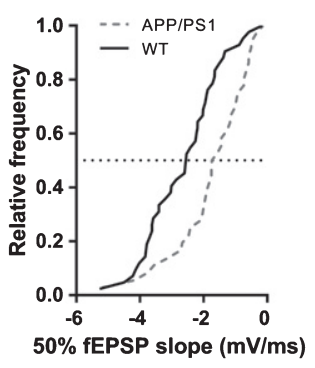

C

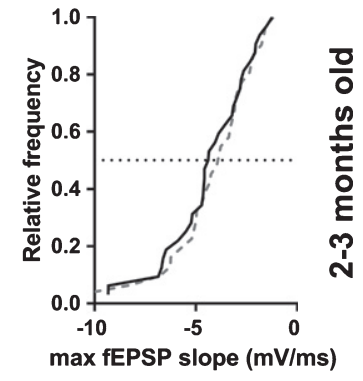

$\mathbf{F}$

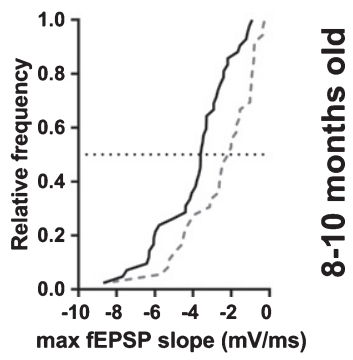

Fig. 4. Post-synaptic responses in CA1 pyramidal cells of hippocampus elicited with Schaffer collaterals stimulation in APP/PS1 mice. A) fEPSP slopes plotted against stimulus amplitude from 2-3-month-old mice (WT $n=32$ slices from 10 animals; APP/PS1 $n=30$ slices from 10 animals; 2-way ANOVA; genotype: $\mathrm{F}(1,1281)=20.45, p<0.0001$; stimulus amplitude: $\mathrm{F}(20,1281)=67.81, p<0.0001$; interaction: $\mathrm{F}(20,1281)=0.3723, p=0.9948$; asterisk indicates result of Bonferroni's multiple comparisons test). B) Cumulative distribution histogram of responses (fEPSP slopes) elicited with a $50 \%$ stimulus amplitude $(200 \mu \mathrm{A})$ in 2-3-month-old animals (K-S test, $\mathrm{D}=0.245, p=0.3012)$. C) Cumulative distribution histogram of responses (fEPSP slopes) elicited with a $100 \%$ stimulus amplitude $(400 \mu \mathrm{A})$ in 2 -3-month-old animals (K-S test, $\mathrm{D}=0.1442, p=0.8990)$. D) fEPSP slopes plotted against stimulus amplitude from 8-10-month-old mice (WT $n=42$ slices from 10 animals; APP/PS1 $n=36$ slices from 9 animals; (2-way ANOVA; genotype: $\mathrm{F}(1,1596)=148.8, p<0.0001$; stimulus amplitude: $\mathrm{F}(20$, $1596)=67.45, p<0.0001$; interaction: $\mathrm{F}(20,1596)=2.692, p<0.0001$; asterisks indicate result of Bonferroni's multiple comparisons test $)$. E) Cumulative distribution histogram of responses (fEPSP slopes) elicited with a 50\% stimulus amplitude (200 $\mu$ A) in 8-10-month-old animals (K-S test, $\mathrm{D}=0.3929, p=0.0050)$. F) Cumulative distribution histogram of responses (fEPSP slopes) elicited with a $100 \%$ stimulus amplitude $(400 \mu \mathrm{A})$ in $8-10$-month-old animals (K-S test, $\mathrm{D}=0.4048, p=0.0035)$.

month-old APP/PS1 with both reduction in fEPSP slope and FV amplitude (Fig. 7). Additionally, we compared the time course of the effects of APP/PS1 and rTg4510 mutations on fEPSP slopes, fiber volley amplitudes and basal synaptic transmission (i.e., fEPSP slopes controlled for fiber volley amplitudes). Figure 8A shows a comparable reduction with age of fEPSP slopes normalized to an age-corresponding WT controls in APP/PS1 and $\mathrm{rTg} 4510$ mice. However, as seen in Fig. 8B, fiber volley amplitudes exhibited a much faster decline in $\mathrm{rTg} 4510$ mice compared to APP/PS1 mice. When fEPSP slopes were controlled for fiber volley amplitudes, a clear distinction in time course of basal synaptic transmission deterioration emerged between APP/PS1 and rTg4510 mice (Fig. 8C). The initial decline in BST between 3 and 10 months of age is much faster in APP/PS1 mice compared to rTg4510 mice, as indicated by linear fits to the first two age points (Fig. 8C).

\section{Short-term synaptic plasticity in young and old APP/PS1 and rTg4510 mice}

Short-term plasticity plays a crucial role in neuronal information processing, relevant to cognitive function. We investigated CA3-CA1 short-term plasticity at different ages in $\mathrm{rTg} 4510$ and APP/PS1 (rTg4510: 2-3 mo and 6-7 mo; APP/PS1 : 2-3 mo and $8-10 \mathrm{mo}$ ) mice utilizing paired pulse stimulation protocol. Paired stimuli were delivered with an inter-stimulus interval of $50 \mathrm{~ms}$ to excite Schaffer collaterals, and the resulting fEPSPs were recorded in stratum radiatum. In 2-3-month-old animals, we did not observe any genotypic difference in resulting paired pulse ratios $\left(\mathrm{fEPSP}_{2} / \mathrm{fEPSP}_{1}\right.$; Fig. 9A, C; $\mathrm{rTg} 4510,1.38 \pm 0.04 \mathrm{SEM}, n=17$ slices versus WT, $1.40 \pm 0.04$ SEM, $n=17$ slices, two-tailed $t$ test, $p=0.7193$; APP/PS1, $1.67 \pm 0.09$ SEM, $n=13$ slices versus WT, $1.70 \pm 0.11 \mathrm{SEM}, n=15$ slices, 
A

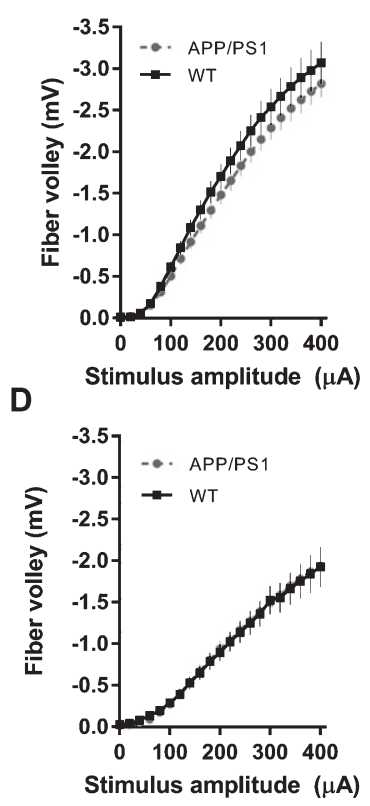

B

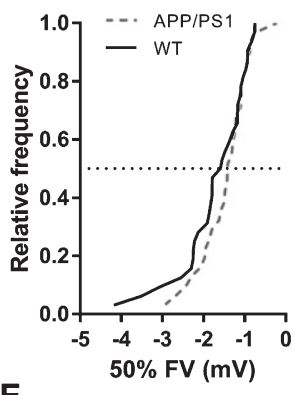

E

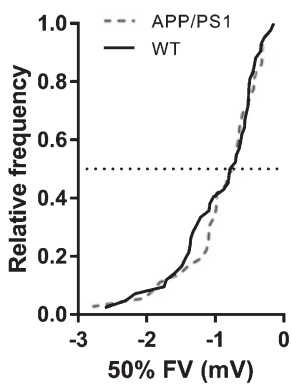

C

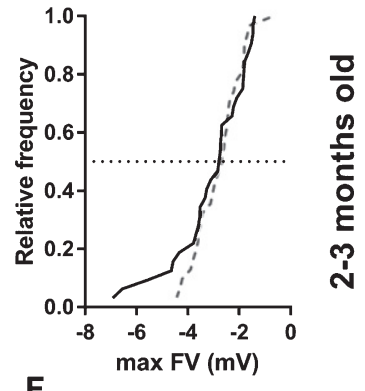

$\mathbf{F}$

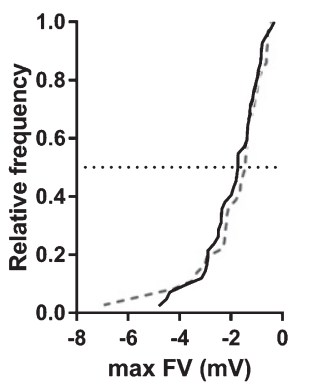

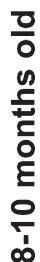

Fig. 5. Activation (fiber volley amplitudes) of Schaffer collaterals in CA1 area in APP/PS1 mice. A) FV amplitudes plotted against stimulus amplitude from 2-3-month-old mice (WT $n=32$ slices from 10 animals; APP/PS1 $n=31$ slices from 10 animals; (2-way ANOVA; genotype: $\mathrm{F}(1,1281)=1728, p<0.0001$; stimulus amplitude: $\mathrm{F}(20,1281)=114.2, p<0.0001$; interaction: $\mathrm{F}(20,1281)=0.267, p=0.995 ;)$. $\mathrm{B})$ Cumulative distribution histogram of FVs elicited with a $50 \%$ stimulus amplitude $(200 \mu \mathrm{A})$ in 2-3-month-old animals $(\mathrm{K}-\mathrm{S}$ test, $\mathrm{D}=0.1784$, $p=0.6978)$. C) Cumulative distribution histogram of FVs elicited with a $100 \%$ stimulus amplitude $(400 \mu \mathrm{A})$ in 2-3-month-old animals (K-S test, $\mathrm{D}=0.1563, p=0.8367$ ). D) FV amplitudes plotted against stimulus amplitude from 8-10-month-old mice (WT $n=42$ slices from 10 animals; APP/PS1 $n=36$ slices from 9 animals; (2-way ANOVA; genotype: $\mathrm{F}(1,1592)=0.068, p=0.7943$; stimulus amplitude: $\mathrm{F}(20$, $1592)=64.19, p<0.0001$; interaction: $\mathrm{F}(20,1592)=0.0241, p>0.9999 ;)$. E) Cumulative distribution histogram of FVs elicited with a $50 \%$ stimulus amplitude $(200 \mu \mathrm{A})$ in $8-10$-month-old animals (K-S test, $\mathrm{D}=0.1667, p=0.6545)$. F) Cumulative distribution histogram of $\mathrm{FVs}$ elicited with a $100 \%$ stimulus amplitude $(400 \mu \mathrm{A})$ in $8-10$-month-old animals (K-S test, $\mathrm{D}=0.1627, p<0.6839)$.

two-tailed $t$-test, $p=0.8550$ ). At 6-7 months of age, rTg4510 mice showed a significant reduction in PPF compared to WT controls (Fig. 9B; $\mathrm{rTg} 4510,1.17 \pm 0.04 \mathrm{SEM}, n=17$ slices versus WT, $1.39 \pm 0.08$ SEM, $n=17$ slices, two-tailed $t$-test, $p=0.0177$ ). Interestingly, 8-10-month-old APP/PS1 mice did not show any deficit in PPF (APP/PS1, $1.39 \pm 0.07$ SEM, $n=17$ slices versus WT, $1.42 \pm 0.10$ SEM, $n=17$ slices, two-tailed $t$-test, $p=0.7936$ ). These data suggest that $\mathrm{P} 301 \mathrm{~L}$ mutation reduces or eliminates synaptic facilitation at these synapses. On the contrary, APP/PS1 mutations do not appear to change the magnitude of facilitation at these synapses.

\section{Long-term potentiation in young and old APP/PS1 and rTg4510 mice}

Loss of memory is a hallmark of AD. It is widely believed that hippocampal long-term potentiation is a cellular/molecular correlate of memory.
We induced CA3-CA1 LTP at different ages in rTg4510 and APP/PS1 (rTg4510:2-3 mo and 6-7 mo; APP/PS1 : 2-3 mo and 8-10 mo) mice with high-frequency stimulation protocol (HFS). Slices prepared from hippocampi of 2-3-month-old rTg4510 mice and WT controls exhibited 50\% fEPSP slope potentiation after $60 \mathrm{~min}$ post last HFS bout, compared to baseline responses (WT: $149.6 \% \pm 5.6$ SEM, $n=29$ slices; $r T g 4510: 151.6 \% \pm 4.6$ SEM, $n=29$ slices). At this age, $\operatorname{rTg} 4510$ mice did not show any deficit in LTP compared to WT controls (Fig. 10A, two-tailed $t$-test, $p=0.7527$ ). In contrast to young mice, slices prepared from older (6-7 mo) rTg4510 mice exhibited 30\% reduction in LTP after $60 \mathrm{~min}$ post last HFS bout, compared to WT controls, which had LTP levels of 50\% above baseline (Fig. 10B; WT: $148.4 \% \pm 9.3$ SEM, $n=18$ slices; $r T g 4510: 117.5 \% \pm 7.0$ SEM, $n=13$ slices; two-tailed $t$-test, $p=0.0199)$. Similarly, slices from young (2-3 mo) APP/PS1 mice did not show LTP deficit compared to WT con- 
trols, with both groups potentiating to more than 50\% above baseline (Fig. 11A; WT: $159.1 \% \pm 7.2$ SEM, $n=31$ slices; APP/PS1 $: 153.0 \% \pm 4.9$ SEM,
A

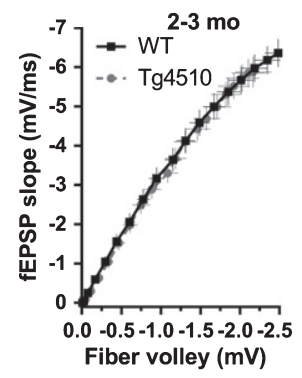

C

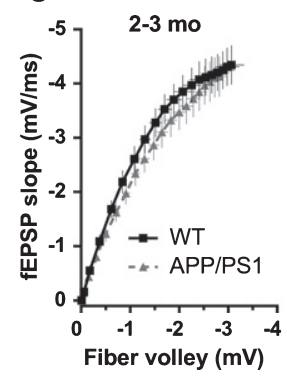

B

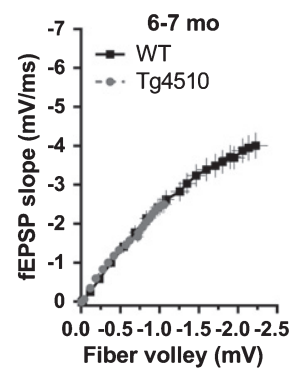

D

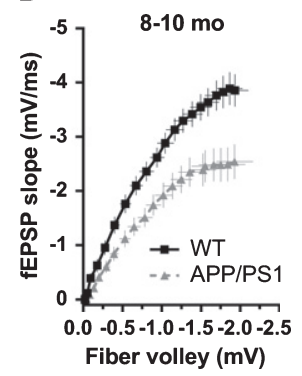

$n=30$ slices; two-tailed $t$-test, $p=0.4819)$. On the contrary, older (8-10 mo) APP/PS1 mice exhibited almost no potentiation after $60 \mathrm{~min}$ post last HFS bout (Fig. 11B; APP/PS1 : 108.1\% \pm 8.4 SEM, $n=11$ slices). Slices prepared from WT controls of this age group showed a normal ( $>50 \%$ ) LTP (Fig. 11B; WT: $158.6 \% \pm 15.4$ SEM, $n=12$ slices; APP/PS1 versus WT: two-tailed $t$-test, $p=0.0107)$. Interestingly, 8-10-month-old APP/PS1 mice also showed a reduced post-tetanic potentiation compared to WT, suggesting that LTP reduction could be due to induction deficits. In summary, our data suggest that in young mice (2-3 mo) neither APP/PS1 nor P301L (rTg4510) mutations produce a deficit in LTP. However, with progression of pathology, LTP deficits appear to emerge, though probably due to different underlying mechanisms. The magnitude of the deficit was found to be similar in 6-7-month-old $\mathrm{rTg} 4510$ mice and 8-10-month-old APP/PS1 mice.

\section{DISCUSSION}

In this study, we examined age-related progressive changes of basal synaptic transmission and shortand long-term plasticity in CA1 area of hippocampus that are presumably caused by specific mutations in APP/PS1 and tau genes, utilizing $\mathrm{APP}_{\text {swe }} / \mathrm{PS} 1_{\mathrm{M} 146 \mathrm{~L}}$ and $\mathrm{rTg}(\operatorname{tauP} 301 \mathrm{~L}) 4510$ mouse models of AD. Our main findings, summarized in Table 1 , indicate that synaptic transmission in remaining CA3-CA1 connections is not altered in $\mathrm{rTg} 4510$ mice at the ages tested, but is reduced in 8-10-month-old APP/PS1 mice. Additionally, rTg4510 exhibits a more acceler-

Fig. 6. Effect of rTg4510 and APP/PS1 mutations on basal synaptic transmission. fEPSP slopes were plotted against fiber volley amplitudes. A) 2-3-month-old rTg4510 and WT controls. B) 6-7month-old rTg4510 and WT controls. C) 2-3-month-old APP/PS1 and WT controls. D) 8-10-month-old APP/PS1 and WT controls. Note that only 8-10-month-old APP/PS1 mice exhibit a genuine reduction in basal synaptic transmission when post-synaptic responses (fEPSP slopes) were controlled for the strength of the pre-synaptic fiber activation (FV amplitude). Data comes from Figs. 1-4. Data is presented as mean \pm s.e.m.
A

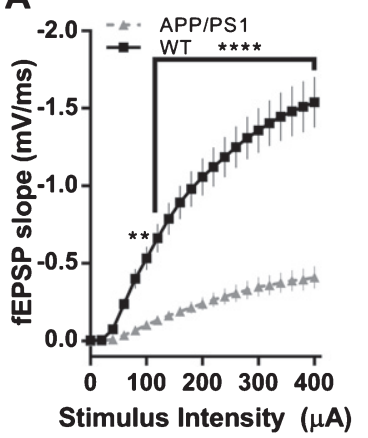

B

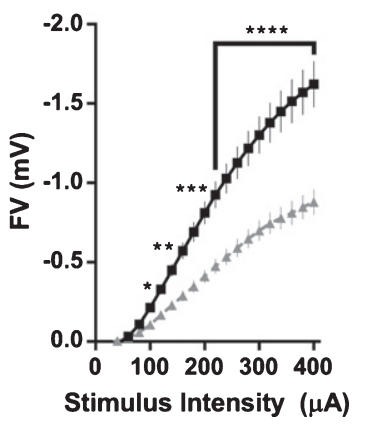

C

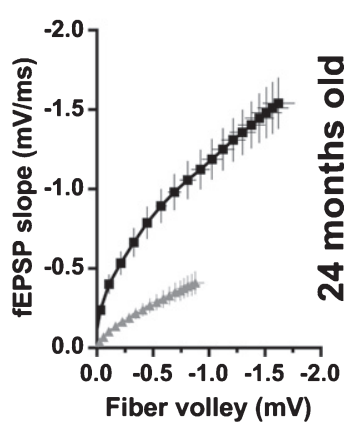

Fig. 7. Effect of APP/PS1 mutations on basal synaptic transmission in 24-month-old mice. A) fEPSP slopes versus stimulus intensity (WT $n=33$ slices from 3 animals; APP/PS1 $n=41$ slices from 4 animals; 2 -way ANOVA; genotype: $\mathrm{F}(1,1512)=778.5, p<0.0001$; stimulus amplitude: $\mathrm{F}(20,1512)=33.96, p<0.0001$; interaction: $\mathrm{F}(20,1512)=11.26, p<0.0001$; asterisks indicate results of Bonferroni's multiple comparisons test). B) Fiber volley amplitudes versus stimulus intensity (WT $n=33$ slices from 3 animals; APP/PS1 $n=41$ slices from 4 animals; 2-way ANOVA; genotype: $\mathrm{F}(1,1512)=319.4, p<0.0001$; stimulus amplitude: $\mathrm{F}(20,1512)=93.74, p<0.0001$; interaction: $\mathrm{F}(20,1512)=8.608, p<0.0001$; asterisks indicate results of Bonferroni's multiple comparisons test). C) fEPSP slopes versus fiber volley amplitudes. 

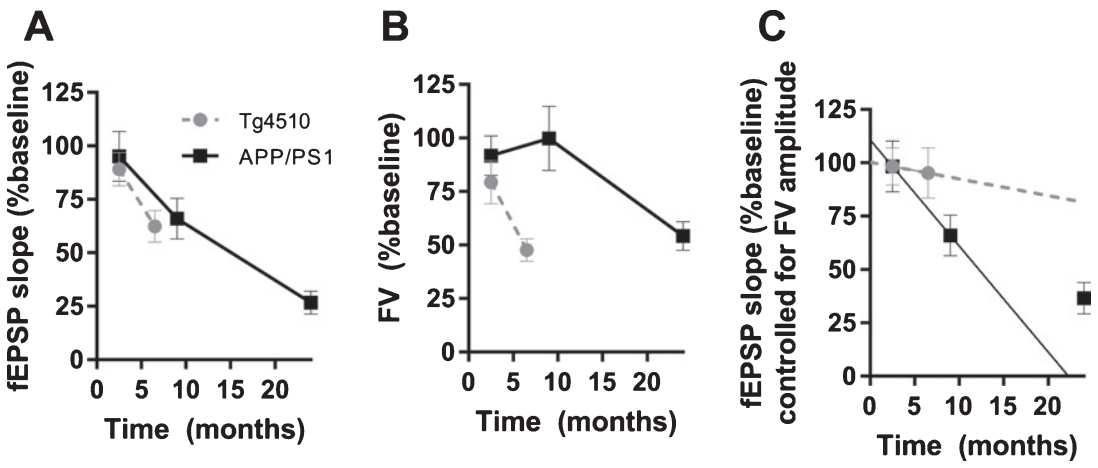

Fig. 8. Age-progression of decline in fEPSP slopes, fiber volley amplitudes (FV) and basal synaptic transmission in APP/PS1 and Tg4510 mice. Data is from Figs. 1-4 and 6. A) fEPSP slopes were normalized to age-corresponding WT controls and plotted against age. B) Fiber volley amplitudes were normalized to age-corresponding WT controls and plotted against age. C) fEPSP slopes controlled for fiber volley amplitudes plotted against age. Lines were fitted to the first two age points to compare initial rate of decline in BST between APP/PS1 and $\mathrm{Tg} 4510$ mice; APP/PS1, $y=-5.0 \mathrm{x}+110.8 ; \mathrm{Tg} 4510, y=-0.8 \mathrm{x}+100.3$; slopes were significantly different, $p<0.05$ ).

A

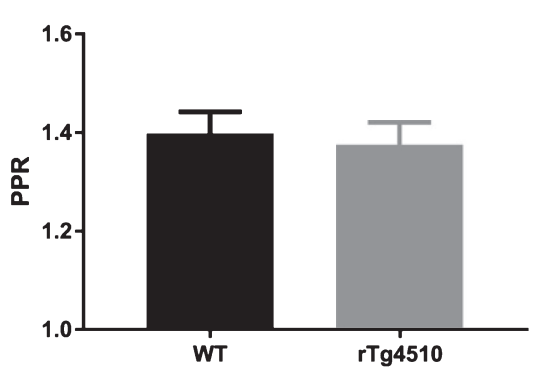

C

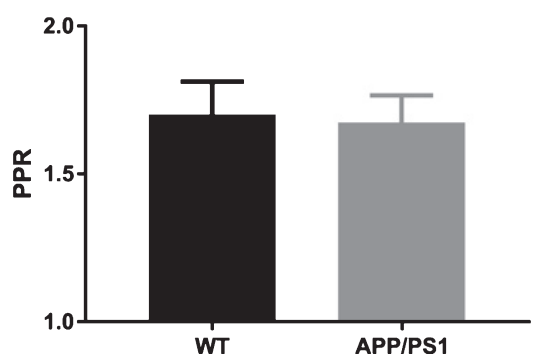

B

6-7 mo

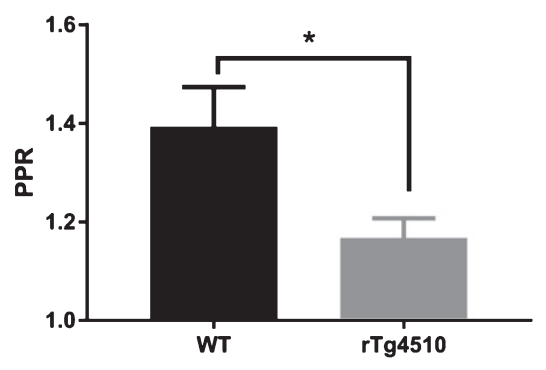

D 8-10 mo

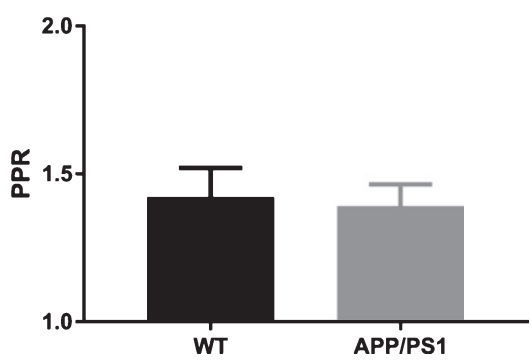

Fig. 9. Short term facilitation in $\mathrm{rTg} 4510$ and APP/PS1 mice. A) 2-3-month-old rTg4510 mice do not show a deficit in paired pulse facilitation (WT: $n=17$ slices from 5 animals, rTg4510: $n=17$ slices from 6 animals; two-tailed $t$-test $p=0.7193$ ). B) 6-7-month-old rTg4510 mice show a deficit in paired pulse facilitation (WT $n=17$ slices from 6 animals, $\operatorname{rTg} 4510 n=17$ slices from 5 animals; two-tailed $t$-test $p=0.0177$ ). C) 2-3-month-old APP/PS1 mice do not show a deficit in paired pulse facilitation (WT $n=15$ slices from 3 animals, APP/PS1 $n=13$ slices from 5 animals; two-tailed $t$-test $p=0.8550$ ). D) 8-10-month-old APP/PS1 mice do not show a deficit in paired pulse facilitation (WT $n=17$ slices from 6 animals, APP/PS1 $n=17$ slices from 5 animals; two-tailed $t$-test $p=0.7936$ ).

ated decline in hippocampal function, observed as a correlated reduction in fEPSP slope and FV, which is consistent with the overall neurodegeneration of hippocampus in this model $[24,25,46]$. Concomitantly, FV reduction may reflect changes in pre-synaptic fiber excitability. It is well established that phospho- rylated tau disrupts axonal cytoskeleton and axonal transport mechanisms [47-49], which may result initially in a lower levels of $\mathrm{Na}^{+}$and/or $\mathrm{K}^{+}$channels, as well as $\mathrm{Na}^{+} / \mathrm{K}^{+}-$ATPases, and axonal mitochondria $[50,51]$, in addition to general structural abnormalities. All of these changes may lead to a reduction 

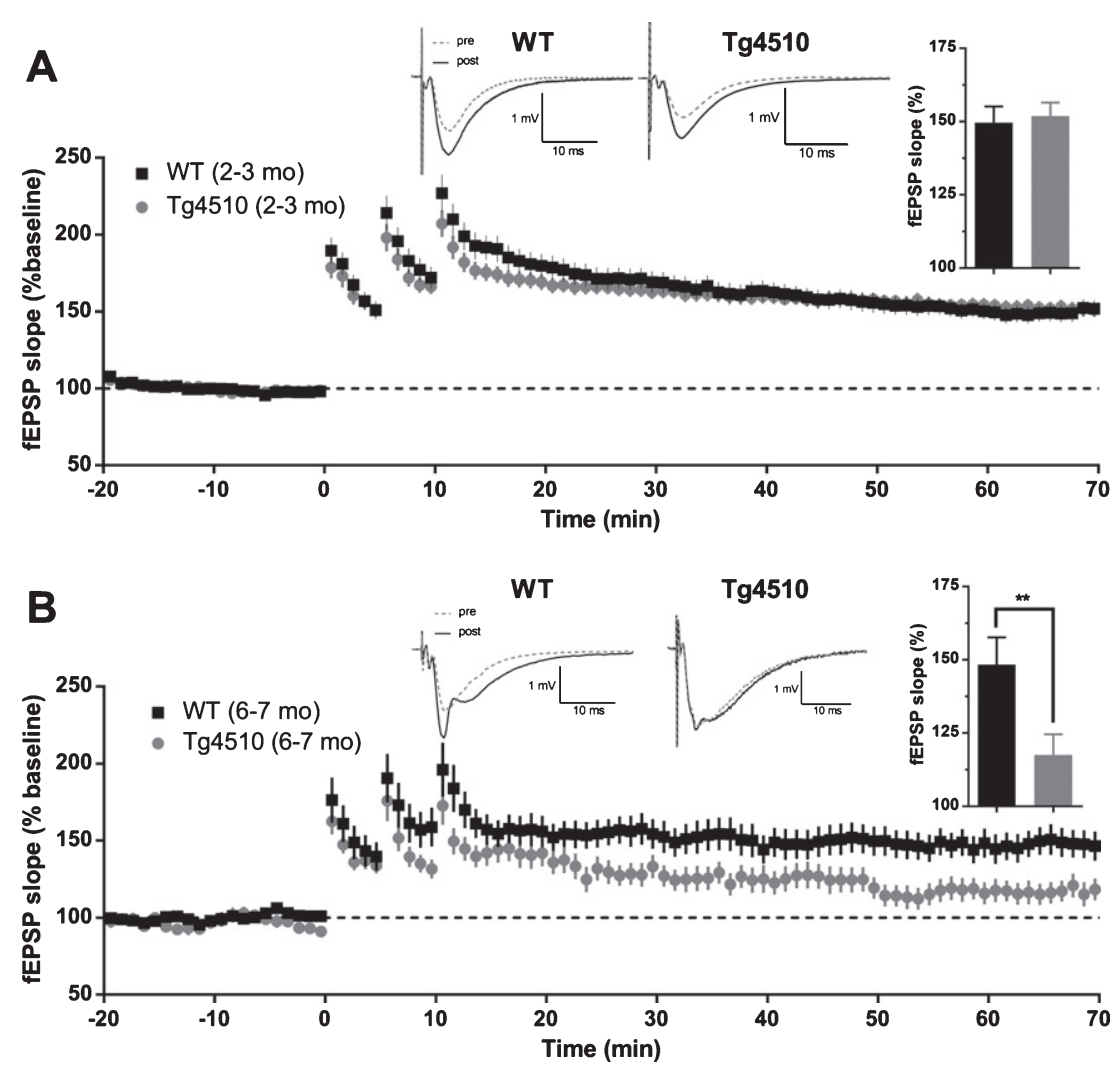

Fig. 10. Long-term potentiation (LTP) in $\mathrm{rTg} 4510$ mice. A) Average baseline-normalized time course of long term potentiation of fEPSP slope in response to high frequency stimulation in 2-3-month-old rTg4510 mice. Example traces represent averaged responses (4 traces) before HFS and at $60 \mathrm{~min}$ post last HFS bout. (Inset). Averaged normalized response from the last 5 min of recordings (WT $n=29$ slices from 9 animals; rTg4510 $n=29$ slices from 9 animals; two-tailed $t$-test $p=0.7527$ ). B) Average baseline-normalized time course of long term potentiation of fEPSP slope in response to high frequency stimulation in 6-7-month-old rTg4510 mice. Example traces represent averaged responses (4 traces) before HFS and at $60 \mathrm{~min}$ post last HFS bout. (Inset). Averaged normalized response from the last 5 min of recordings (WT $n=18$ slices from 7 animals; rTg4510 $n=13$ slices from 7 animals; two-tailed $t$-test $p=0.0199$ ).

in axonal excitability and eventually to axonal degeneration.

We find that in young 2-3-month-old APP/PS1 mice neither pre-synaptic activation (fiber volley amplitude) nor post-synaptic responses (fEPSP slope) were affected. However, young 2-3-monthold rTg4510 mice, already at this age, show a small deficit in fiber volley amplitude, with no concomitant change in post-synaptic response. In 8-10-monthold APP/PS1 mice fEPSP slope was significantly reduced, but fiber volley amplitudes were not different from WT controls. This suggests that at this age APP/PS1 mice show a genuine synaptic dysfunction. At 24 months, a clear reduction in fEPSP slope and FV amplitude was observed in APP/PS1, consistent with neurodegeneration of CA1 area of hippocampus at this age [32]. In 6-7-month-old rTg4510 mice, a concomitant reduction in fEPSP slope and fiber volley amplitude was observed, which is consistent with previous reports $[24,46]$ of rapid progressive hippocampal neurodegeneration in this model. However, plots of fEPSP slopes versus fiber volley amplitudes indicated no change in basal synaptic transmission. Several previous studies have examined aspects of hippocampal physiology in $\mathrm{rTg} 4510$ mice. Dalby et al. [28] performed an electrophysiological analysis of CA3-CA1 area of hippocampus in 2.5-3 and 5.5-6-month-old rTg4510 mice. They reported reduction in BST (fEPSP slope), as early as 2.5-3 months of age. This conclusion was based on input-output relation between fEPSP slope and stimulus intensity. Booth et al. [34] reported similar fEPSP slope deficits in 7-8-month-old mice and also concluded that BST is diminished. However, neither of these authors took into account the strength of pre-synaptic activation (i.e., FV amplitudes). In con- 


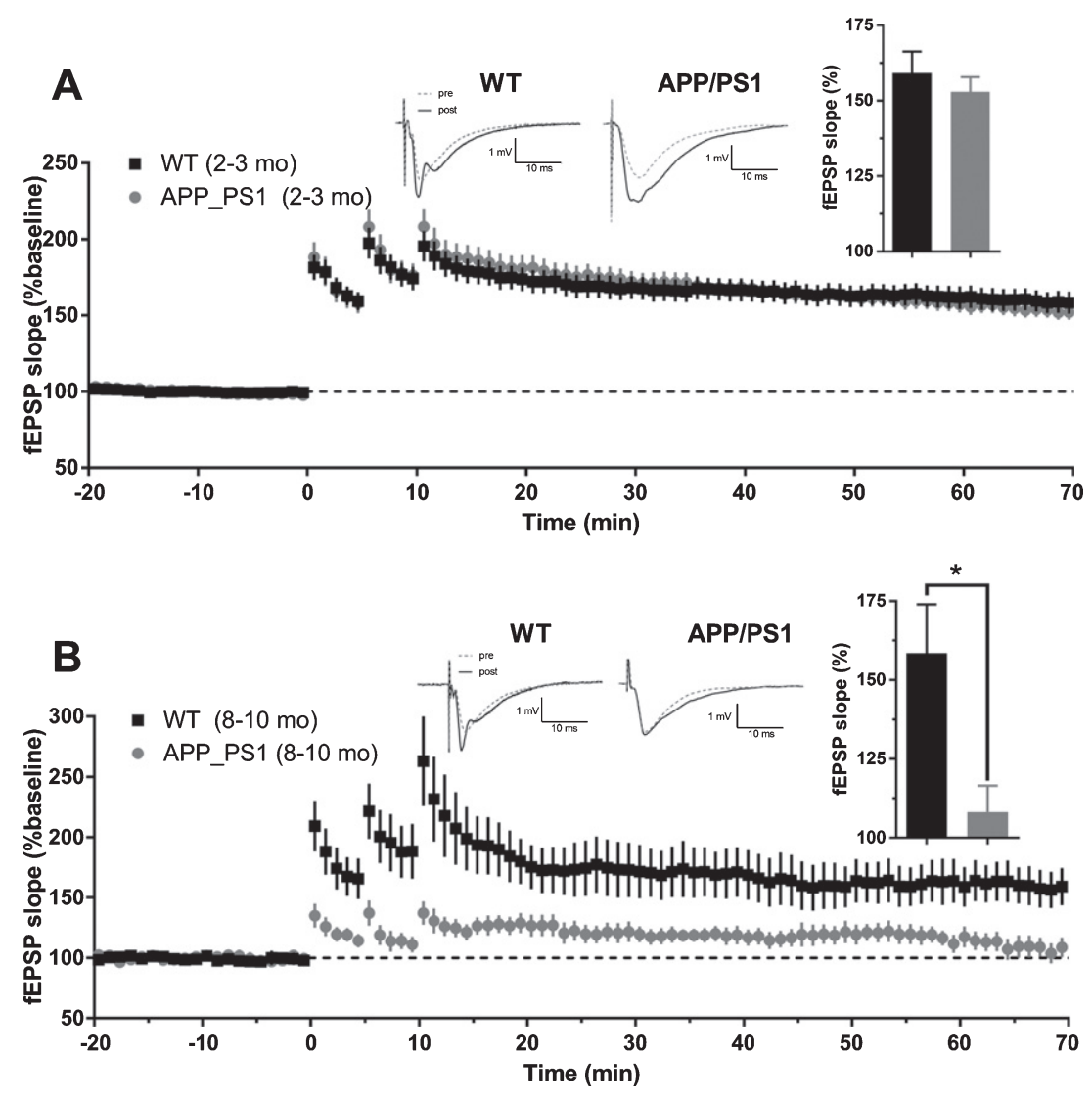

Fig. 11. Long-term potentiation in APP/PS1 mice. A) Average baseline-normalized time course of long term potentiation of fEPSP slope in response to high frequency stimulation in 2-3-month-old APP/PS1 mice. Example traces represent averaged responses (4 traces) before HFS and at $60 \mathrm{~min}$ post last HFS bout. (Inset). Averaged normalized response from the last $5 \mathrm{~min}$ of recordings (WT $n=31$ slices from 10 animals; APP/PS1 $n=30$ slices from 9 animals; two-tailed $t$-test $p=0.4819$ ). B) Average baseline-normalized time course of long-term potentiation of fEPSP slope in response to high frequency stimulation in 8-10-month-old APP/PS1 mice. Example traces represent averaged responses ( 4 traces) before HFS and at 60 min post last HFS bout. (Inset). Averaged normalized response from the last 5 min of recordings (WT $n=12$ slices from 6 animals; APP/PS1 $n=11$ slices from 7 animals; two-tailed $t$-test $p=0.0107$ ).

trast to their findings, our data indicate no changes in BST in 6-7-month-old mice, when corrected for changes in FV amplitude, suggesting that remaining CA3-CA1 connections may support normal basal levels of neurotransmission.

PPF was reduced in rTg4510 at 6-7 months of age, pointing to potential abnormalities in pre-synaptic release machinery that are relevant to short-term plasticity. This deficit may be due to abnormal calcium homeostasis, which has been shown in cultured cells to co-occur with overexpression, hyperphosphorylation, misfolding, and mislocalization of tau [52-54]. However, in 8-9-month-old rTg4510 mice, cortical neurons exhibit loss of dendritic spines that is calcium-independent [55]. Thus, the possibility of calcium independent mechanisms of PPF reduction in Schaffer collaterals of hippocampus can-
Table 1

Qualitative summary of electrophysiological measures in young and old APP/PS1 and rTg4510 mice. Equal sign (=) or arrow $(\downarrow)$ denote no difference or a statistically significant decrease, respectively, in mutant mice relative to WT controls

\begin{tabular}{lcccccc}
\hline & APP/PS1 & rTg4510 & \multicolumn{2}{c}{ APP/PS1 } & rTg4510 \\
\cline { 3 - 4 } Age (mo) & & $2-3$ & & $8-10$ & 24 & $6-7$ \\
\hline FV amplitude & $=$ & $=$ & $=$ & $\downarrow$ & $\downarrow$ \\
fEPSP slope & $=$ & $=$ & $\downarrow$ & $\downarrow$ & $\downarrow$ \\
$\quad$ versus stim & & & & & & \\
fEPSP versus FV & $=$ & $=$ & $\downarrow$ & $\downarrow$ & $=$ \\
LTP & $=$ & $=$ & $\downarrow$ & & $\downarrow$ \\
PPF & $=$ & $=$ & $=$ & & $\downarrow$ \\
\hline
\end{tabular}

Note: LTP and PPF were not examined in 24-month-old APP/PS1.

not be excluded. Additionally, we cannot rule out alterations in transmitter release in 6-7-month-old rTg4510 mice, since PPF was reduced, however such 
changes, do not seem to affect BST in this AD model. One might speculate that an increase in release probability in $\mathrm{rTg} 4510$ mice could, in principle, have offset reductions in CA3 axon number or excitability, either of which could underlie reduced FV amplitude.

In contrast to 6-7-month-old rTg4510 mice, PPF was not affected in APP/PS1 mice at least up to 8-9 months of age. Given that BST was impaired in APP/PS1, this suggests that the basis of the BST deficit in APP/PS1 mice is largely post-synaptic.

APP/PS1 (8-10 mo) and rTg4510 mice (6-7 mo) both showed deficits in LTP. In rTg4510 mice the capacity for LTP induction, as judged by equivalent levels of early post-tetanic potentiation, is presumably not impaired, which suggests that LTP deficiency in this model is most likely due to altered postsynaptic signaling pathways. In contrast APP/PS1, showed a much-diminished post-tetanic potentiation, suggesting that in this model LTP reduction may be due to induction deficits (either pre and/or post-synaptic), consistent with observed reduced basal synaptic transmission.

Trinchese et al. [27] examined age-dependent progression of $\mathrm{A} \beta$ deposition in APP/PS1 mice and attempted to correlate it with electrophysiological and behavioral markers. They reported reduced levels of LTP as early as 3-4 months of age with no reduction in BST at this age. LTP deficit was correlated with plaque appearance, elevated levels of $A \beta$ and abnormal short-term memory. BST was affected only at about 5-6 months of age. Our results are consistent with this timeline, i.e., we did not observe LTP deficits and BST reduction in 2-3-month-old APP/PS1 mice. Additionally, since older mice in our study were 8-10 months old, BST and LTP deficits that we observe are in line with Trinchese et al. Similar to our findings, Trinchese et al. reported no changes in PPF at any age in APP/PS1.

Our comparison of these two mouse models points to a major difference in the effects of their respective mutations on basal synaptic transmission. Our data reveal that in $\mathrm{rTg} 4510$ mice, basal synaptic transmission is not affected up to 6-7 months of age, in contrast to APP/PS1, in which a deficit in basal synaptic transmission occurs before 6 months of age. In rTg4510, a small reduction in fiber volley amplitude can be detected as early as 2-3 months of age. In contrast, fiber volley amplitude decline in APP/PS1 mice was detected only by 24 months. Overall, these data suggest that synaptic transmission deficits in these models progress at different rates. These func- tional distinctions may influence how these models are deployed in evaluating therapeutic compounds.

\section{DISCLOSURE STATEMENT}

Authors' disclosures available online (http://j-alz. com/manuscript-disclosures/17-0457r2).

\section{REFERENCES}

[1] Selkoe DJ (2001) Alzheimer's disease: Genes, proteins, and therapy. Physiol Rev 81, 741-766.

[2] Selkoe D, Mandelkow E, Holtzman D (2012) Deciphering Alzheimer disease. Cold Spring Harb Perspect Med 2, a011460.

[3] Kidd M (1964) Alzheimer's disease — an electron microscopical study. Brain 87, 307-320.

[4] Terry RD (1963) The fine structure of neurofibrillary tangles in Alzheimer's disease. J Neuropathol Exp Neurol 22, 629642.

[5] Karlinsky H, Vaula G, Haines JL, Ridgley J, Bergeron C, Mortilla M, Tupler RG, Percy ME, Robitaille Y, Noldy NE, Yip, Tanzi RE, Gusella JF, Becker R, Berg JM, Mclachlan DR, St Gearge-Hyslop PH (1992) Molecular and prospective phenotypic characterization of a pedigree with familial Alzheimer's disease and a missense mutation in codon 717 of the beta-amyloid precursor protein gene. Neurology $\mathbf{4 2}$, 1445-1453.

[6] Farlow M, Murrell J, Ghetti B, Unverzagt F, Zeldenrust S, Benson M (1994) Clinical characteristics in a kindred with early-onset Alzheimer's disease and their linkage to a G$>\mathrm{T}$ change at position 2149 of the amyloid precursor protein gene. Neurology 44, 105-111.

[7] Rossi G, Giaccone G, Maletta R, Morbin M, Capobianco R, Mangieri M, Giovagnoli AR, Bizzi A, Tomaino C, Perri M, Di Natale M, Tagliavini F, Bugiani O, Bruni AC (2004) A family with Alzheimer disease and strokes associated with A713T mutation of the APP gene. Neurology 63, 910-912.

[8] Mullan M, Crawford F, Axelman K, Houlden H, Lilius L, Winblad B, Lannfelt L (1992) A pathogenic mutation for probable Alzheimer's disease in the APP gene at the N-terminus of beta-amyloid. Nat Genet 1, 345-347.

[9] Robakis NK, Ramakrishna N, Wolfe G, Wisniewski HM (1987) Molecular cloning and characterization of a cDNA encoding the cerebrovascular and the neuritic plaque amyloid peptides. Proc Natl Acad Sci U S A 84, 4190-4194.

[10] Goldgaber D, Lerman MI, McBride OW, Saffiotti U, Gajdusek DC (1987) Characterization and chromosomal localization of a cDNA encoding brain amyloid of Alzheimer's disease. Science 235, 877-880.

[11] Sherrington R, Rogaev EI, Liang Y, Rogaeva EA, Levesque G, Ikeda M, Chi H, Lin C, Li G, Holman K, Tsuda T, Mar L, Foncin JF, Bruni AC, Montesi MP, Sorbi S, Rainero I, Pinessi L, Nee L, Chumakov I, Pollen D, Brookes A, Sanseau P, Polinsky RJ, Wasco W, Da Silva HA, Haines JL, Perkicak-Vance MA, Tanzi RE, Roses AD, Fraser PE, Rommens JM, St George-Hyslop PH (1995) Cloning of a gene bearing missense mutations in early-onset familial Alzheimer's disease. Nature 375, 754-760.

[12] Clark RF, Hutton M, Fuldner M, Froelich S, Karran E, Talbot C, Crook R, Lendon C, Prihar G, He C, Korenblat K, Mar- 
tinez A, Wragg M, Busfield F, Behrens MI, Myers A, Norton J, Morris J, Mehta N, Pearson C, Lincoln S, Baker M, Duff K, Zehr C, Perez-Tur J, Houlden H, Ruiz A, Ossa J, Lopera F, Arcos M, Madrigal L, Collinge J, Humphreys C, Ashworth A, Sarner S, Fox N, Harvey R, Kennedy A, Roques P, Cline RT, Philips CA, Venter JC, Forsell L, Axelman K, Lilius L, Johnston J, Cowburn R, Viitanen M, Winblad B, Kosik K, Haltia M, Poyhonen M, Dickson D, Mann D, Neary D, Snowden J, Lantos P, Lannfelt L, Rossor M, Roberts GW, Adams MD, Hardy J, Goate A (1995) The structure of the presenilin 1 (S182) gene and identification of six novel mutations in early onset AD families. Nat Genet 11, 219-222.

[13] Levy-Lahad E, Wasco W, Poorkaj P, Romano DM, Oshima J, Pettingell WH, Yu CE, Jondro PD, Schmidt SD, Wang K, Crowley AC, Fu YH, Guenette SY, Galas D, Nemens E, Wijsman EM, Bird TD, Schellenberg GD, Tanzi RE (1995) Candidate gene for the chromosome 1 familial Alzheimer's disease locus. Science 269, 973-977.

[14] Levy-Lahad E, Wijsman EM, Nemens E, Anderson L, Goddard KA, Weber JL, Bird TD, Schellenberg GD (1995) A familial Alzheimer's disease locus on chromosome 1. Science 269, 970-973.

[15] Hutton M, Lendon CL, Rizzu P, Baker M, Froelich S, Houlden H, Pickering-Brown S, Chakraverty S, Isaacs A, Grover A, Hackett J, Adamson J, Lincoln S, Dickson D, Davies P, Petersen RC, Stevens M, de Graaff E, Wauters E, van Baren J, Hillebrand M, Joosse M, Kwon JM, Nowotny P, Che LK, Norton J, Morris JC, Reed LA, Trojanowski J, Basun H, Lannfelt L, Neystat M, Fahn S, Dark F, Tannenberg T, Dodd PR, Hayward N, Kwok JB, Schofield PR, Andreadis A, Snowden J, Craufurd D, Neary D, Owen F, Oostra BA, Hardy J, Goate A, van Swieten J, Mann D, Lynch T, Heutink P (1998) Association of missense and 5[prime]splice-site mutations in tau with the inherited dementia FTDP-17. Nature 393, 702-705.

[16] Foster NL, Wilhelmsen K, Sima AAF, Jones MZ, D'Amato CJ, Gilman S (1997) Frontotemporal dementia and parkinsonism linked to chromosome 17: A consensus conference. Ann Neurol 41, 706-715.

[17] Iqbal K, Grundke-Iqbal I, Zaidi T, Merz PA, Wen GY, Shaikh SS, Wisniewski HM, Alafuzoff I, Winblad B (1986) Defective brain microtubule assembly in Alzheimer's disease. Lancet 2, 421-426.

[18] Grundke-Iqbal I, Iqbal K, Tung YC, Quinlan M, Wisniewski HM, Binder LI (1986) Abnormal phosphorylation of the microtubule-associated protein tau (tau) in Alzheimer cytoskeletal pathology. Proc Natl Acad Sci U S A 83, 49134917.

[19] Iqbal K, Alonso Adel C, Chen S, Chohan MO, El-Akkad E, Gong CX, Khatoon S, Li B, Liu F, Rahman A, Tanimukai H, Grundke-Iqbal I (2005) Tau pathology in Alzheimer disease and other tauopathies. Biochim Biophys Acta 1739, 198-210.

[20] Grundke-Iqbal I, Iqbal K, Quinlan M, Tung YC, Zaidi MS, Wisniewski HM (1986) Microtubule-associated protein tau. A component of Alzheimer paired helical filaments. J Biol Chem 261, 6084-6089.

[21] Holcomb L, Gordon MN, McGowan E, Yu X, Benkovic S, Jantzen P, Wright K, Saad I, Mueller R, Morgan D, Sanders S, Zehr C, O'Campo K, Hardy J, Prada CM, Eckman C, Younkin S, Hsiao K, Duff K (1998) Accelerated Alzheimertype phenotype in transgenic mice carrying both mutant amyloid precursor protein and presenilin 1 transgenes. Nat Med 4, 97-100.
[22] Gordon MN, Holcomb LA, Jantzen PT, DiCarlo G, Wilcock D, Boyett KW, Connor K, Melachrino J, O'Callaghan JP, Morgan D (2002) Time course of the development of Alzheimer-like pathology in the doubly transgenic PS1+APP mouse. Exp Neurol 173, 183-195.

[23] Borchelt DR, Ratovitski T, van Lare J, Lee MK, Gonzales V, Jenkins NA, Copeland NG, Price DL, Sisodia SS (1997) Accelerated amyloid deposition in the brains of transgenic mice coexpressing mutant presenilin 1 and amyloid precursor proteins. Neuron 19, 939-945.

[24] SantaCruz K, Lewis J, Spires T, Paulson J, Kotilinek L, Ingelsson M, Guimaraes A, DeTure M, Ramsden M, McGowan E, Forster C, Yue M, Orne J, Janus C, Mariash A, Kuskowski M, Hyman B, Hutton M, Ashe KH (2005) Tau suppression in a neurodegenerative mouse model improves memory function. Science 309, 476-481.

[25] Ramsden M, Kotilinek L, Forster C, Paulson J, McGowan E, SantaCruz K, Guimaraes A, Yue M, Lewis J, Carlson G, Hutton M, Ashe KH (2005) Age-dependent neurofibrillary tangle formation, neuron loss, and memory impairment in a mouse model of human tauopathy (P301L). J Neurosci 25, 10637-10647.

[26] Polydoro M, Acker CM, Duff K, Castillo PE, Davies P (2009) Age-dependent impairment of cognitive and synaptic function in the htau mouse model of tau pathology. J Neurosci 29, 10741-10749.

[27] Trinchese F, Liu S, Battaglia F, Walter S, Mathews PM, Arancio O (2004) Progressive age-related development of Alzheimer-like pathology in APP/PS1 mice. Ann Neurol 55, 801-814.

[28] Dalby NO, Volbracht C, Helboe L, Larsen PH, Jensen HS, Egebjerg J, Elvang AB (2014) Altered function of hippocampal CA1 pyramidal neurons in the $\mathrm{rTg} 4510$ mouse model of tauopathy. $J$ Alzheimers Dis 40, 429-442.

[29] Wengenack TM, Whelan S, Curran GL, Duff KE, Poduslo JF (2000) Quantitative histological analysis of amyloid deposition in Alzheimer's double transgenic mouse brain. Neuroscience 101, 939-944.

[30] Marchetti C, Marie H (2011) Hippocampal synaptic plasticity in Alzheimer's disease: What have we learned so far from transgenic models? Rev Neurosci 22, 373-402.

[31] Huang H, Nie S, Cao M, Marshall C, Gao J, Xiao N, Hu G, Xiao M (2016) Characterization of AD-like phenotype in aged APPSwe/PS1dE9 mice. AGE 38, 303-322.

[32] Sadowski M, Pankiewicz J, Scholtzova H, Ji Y, Quartermain D, Jensen CH, Duff K, Nixon RA, Gruen RJ, Wisniewski T (2004) Amyloid- $\beta$ deposition is associated with decreased hippocampal glucose metabolism and spatial memory impairment in APP/PS1 mice. J Neuropathol Exp Neurol 63, 418-428.

[33] Huang H, Wang L, Cao M, Marshall C, Gao J, Xiao N, Hu G, Xiao M (2015) Isolation housing exacerbates Alzheimer's disease-like pathophysiology in aged APP/PS1 mice. Int $J$ Neuropsychopharmacol 18, pyu 116.

[34] Booth CA, Witton J, Nowacki J, Tsaneva-Atanasova K, Jones MW, Randall AD, Brown JT (2016) Altered intrinsic pyramidal neuron properties and pathway-specific synaptic dysfunction underlie aberrant hippocampal network function in a mouse model of tauopathy. J Neurosci 36, 350-363.

[35] Hoover BR, Reed MN, Su J, Penrod RD, Kotilinek LA, Grant MK, Pitstick R, Carlson GA, Lanier LM, Yuan LL, Ashe KH, Liao D (2010) Tau mislocalization to dendritic spines mediates synaptic dysfunction independently of neurodegeneration. Neuron 68, 1067-1081. 
[36] Duff K, Hardy J (1999) Transgenic mice expressing APPK670N,M671L and a mutant presenilin transgenes. USPTO Patent \# 5, 898,094.

[37] Adesnik H, Nicoll RA (2007) Conservation of glutamate receptor 2-containing AMPA receptors during long-term potentiation. J Neurosci 27, 4598-4602.

[38] Crozier RA, Wang Y, Liu CH, Bear MF (2007) Deprivationinduced synaptic depression by distinct mechanisms in different layers of mouse visual cortex. Proc Natl Acad Sci U S A 104, 1383-1388.

[39] Malleret G, Alarcon JM, Martel G, Takizawa S, Vronskaya S, Yin D, Chen IZ, Kandel ER, Shumyatsky GP (2010) Bidirectional regulation of hippocampal long-term synaptic plasticity and its influence on opposing forms of memory. J Neurosci 30, 3813-3825.

[40] Takeuchi K, Yang Y, Takayasu Y, Gertner M, Hwang JY, Aromolaran K, Bennett MV, Zukin RS (2015) Estradiol pretreatment ameliorates impaired synaptic plasticity at synapses of insulted CA1 neurons after transient global ischemia. Brain Res 1621, 222-230.

[41] Winder DG, Mansuy IM, Osman M, Moallem TM, Kandel ER (1998) Genetic and pharmacological evidence for a novel, intermediate phase of long-term potentiation suppressed by calcineurin. Cell 92, 25-37.

[42] Tombaugh GC, Rowe WB, Chow AR, Michael TH, Rose GM (2002) Theta-frequency synaptic potentiation in CA1 in vitro distinguishes cognitively impaired from unimpaired aged Fischer 344 rats. J Neurosci 22, 9932-9940.

[43] Abel T, Nguyen PV, Barad M, Deuel TAS, Kandel ER, Bourtchouladze R (1997) Genetic demonstration of a role for PKA in the late phase of LTP and in hippocampus-based long-term memory. Cell 88, 615-626.

[44] Barad M, Bourtchouladze R, Winder DG, Golan H, Kandel E (1998) Rolipram, a type IV-specific phosphodiesterase inhibitor, facilitates the establishment of long-lasting longterm potentiation and improves memory. Proc Natl Acad Sci U S A 95, 15020-15025.

[45] Nguyen P, Abel T, Kandel E (1994) Requirement of a critical period of transcription for induction of a late phase of LTP. Science 265, 1104-1107.

[46] Helboe L, Egebjerg J, Barkholt P, Volbracht C (2017) Early depletion of CA1 neurons and late neurodegeneration in a mouse tauopathy model. Brain Res $\mathbf{1 6 6 5}, 22-35$.
[47] Cowan CM, Bossing T, Page A, Shepherd D, Mudher A (2010) Soluble hyper-phosphorylated tau causes microtubule breakdown and functionally compromises normal tau in vivo. Acta Neuropathol 120, 593-604.

[48] Morfini GA, Burns M, Binder LI, Kanaan NM, LaPointe N, Bosco DA, Brown RH, Brown H, Tiwari A, Hayward L, Edgar J, Nave KA, Garberrn J, Atagi Y, Song Y, Pigino G, Brady ST (2009) Axonal transport defects in neurodegenerative diseases. J Neurosci 29, 12776-12786.

[49] LaPointe NE, Morfini G, Pigino G, Gaisina IN, Kozikowski AP, Binder LI, Brady ST (2009) The amino terminus of tau inhibits kinesin-dependent axonal transport: Implications for filament toxicity. J Neurosci Res 87, 440-451.

[50] Shafiei SS, Guerrero-Muñoz MJ, Castillo-Carranza DL (2017) Tau oligomers: Cytotoxicity, propagation, and mitochondrial damage. Front Aging Neurosci 9, 83.

[51] Lasagna-Reeves CA, Castillo-Carranza DL, Sengupta U, Clos AL, Jackson GR, Kayed R (2011) Tau oligomers impair memory and induce synaptic and mitochondrial dysfunction in wild-type mice. Mol Neurodegener 6, 39.

[52] Zempel H, Thies E, Mandelkow E, Mandelkow EM (2010) Abeta oligomers cause localized $\mathrm{Ca}(2+)$ elevation, missorting of endogenous Tau into dendrites, Tau phosphorylation, and destruction of microtubules and spines. J Neurosci $\mathbf{3 0}$, 11938-11950.

[53] Quintanilla RA, Matthews-Roberson TA, Dolan PJ, Johnson GV (2009) Caspase-cleaved tau expression induces mitochondrial dysfunction in immortalized cortical neurons: Implications for the pathogenesis of Alzheimer disease. J Biol Chem 284, 18754-18766.

[54] Gomez-Ramos A, Diaz-Hernandez M, Rubio A, MirasPortugal MT, Avila J (2008) Extracellular tau promotes intracellular calcium increase through M1 and M3 muscarinic receptors in neuronal cells. Mol Cell Neurosci 37, 673-681.

[55] Kopeikina KJ, Wegmann S, Pitstick R, Carlson GA, Bacskai BJ, Betensky RA, Hyman BT, Spires-Jones TL (2013) Tau causes synapse loss without disrupting calcium homeostasis in the rTg4510 model of tauopathy. PLoS One 8, e80834. 